\title{
Prirodni inokulum entomopatogenih gljiva u prezimljavajućoj populaciji hrastove mrežaste stjenice Corythucha arcuata (Heteroptera, Tingidae)
}

\author{
Natural inoculum of entomopathogenic fungi in the overwintering \\ population of oak lace bug Corythucha arcuata (Heteroptera, Tingidae)
}

\author{
Marta Kovač \\ Hrvatski šumarski institut, Zavod za zaštitu šuma i lovno gospodarenje, Cvjetno naselje 41, 10450 Jastrebarsko \\ * Corresponding author E-mail address: martam@sumins.hr (M. Kovač)
}

\section{Sažetak}

Prirodni neprijatelji invazivne hrastove mrežaste stjenice, Corythucha arcuata (Heteroptera, Tingidae) do sada su slabo istraživani, no otkriće entomopatogenih gljiva kao uzročnika uginuća odraslih jedinki nađenih na području spačvanskog bazena produbilo je potrebu za provedbom entomopatoloških istraživanja. Cilj ovog istraživanja bio je utvrditi brojnost hrastove mrežaste stjenice, prirodni mortalitet i prirodni inokulum entomopatogenih gljiva, odnosno njihovu prisutnost u populaciji računajući prosječan broj prezimljavajućih, mrtvih i zaraženih jedinki u $1 \mathrm{~m}^{2}$ mahovine na odabranim lokalitetima spačvanskog bazena. Istraživanje je provedeno u ožujku 2021. godine, a podaci su uspoređivani s onima iz ožujka 2019. godine. Rezultati su pokazali da na tim lokalitetima postoji određeni pad gustoće populacije ovog štetnika, a prezimljavajuću generaciju bilježi vrlo visoki mortalitet od $64 \%$. Također, utvrđeno je povećanje prirodnog inokuluma entomopatogenih gljiva s $13 \%$ na $19 \%$ populacije, a u ukupnom udjelu zaraženih jedinki njih čak $75 \%$ bilo je zaraženo gljivama roda $\mathrm{Be}-$ auveria. Navedeno povećanje prirodnog inokuluma ukazuje na redukcijski potencijal entomopatogenih gljiva i ulogu koji ti organizmi imaju u prirodnoj regulaciji populacija hrastove mrežaste stjenice, a koja bi s vremenom mogla biti sve važnija.

Ključne riječi: hrast lužnjak, spačvanski bazen, invazivni štetnik, entomopatologija

\section{Abstract}

The natural enemies of invasive oak lace bug, Corythucha arcuata (Heteroptera, Tingidae) have so far been poorly studied, but the discovery of entomopathogenic fungi as the cause of death of adult individuals found in the Spačva basin has deepened the need for entomopathological research. The aim of this study was to determine the oak lace bug population abundance, natural mortality and natural inoculum of entomopathogenic fungi, i.e. their presence in the oak lace bug population, by counting the average number of overwintering, dead and infected individuals in $1 \mathrm{~m}^{2}$ of moss at selected sites of the Spačva basin. The data were compared with those from March 2019 , and the results showed that in these localities there is a certain decrease in the population density of this pest, and the overwintering generation has a very high mortality of $64 \%$. Also, there was an increase of the natural inoculum of entomopathogenic fungi from $13 \%$ to $19 \%$ of the population, and in the total share of infected 
individuals $75 \%$ of them were infected with Beauveria fungi. This increase of natural inoculum indicates the reduction potential of entomopathogenic fungi and the role that these organisms play in the natural regulation of oak lace bug populations that could become increasingly important over time.

Keywords: Pedunculate oak, Spačva basin, invasive pest, entomopathology

\section{Uvod - Introduction}

Entomopatogene gljive skupina su filogenetski raznolikih eukariotskih heterotrofnih mikroorganizama koji su uzročnici bolesti na kukcima, a mogu imati važnu ulogu u njihovoj populacijskoj dinamici u prirodnim ekosustavima (Samson i sur. 1988; Wraight i sur. 2007). Od procijenjenih 1.5 - 5.1 milijuna i opisanih otprilike 100000 vrsta pripadnika carstva gljiva (Fungi), njih oko 750 - 1000 pripada entomopatogenim gljivama smještenima u preko 100 rodova (Roberts i Humber 1981; McCoy i sur. 1988; St. Leger i Wang 2010). Prema dosadašnjim istraživanjima otprilike $80 \%$ bolesti koje se javljaju kod kukaca za uzročnika imaju patogene gljive. Gotovo na svakoj vrsti kukaca dolazi neka vrsta entomopatogenih gljiva, od kojih neke osim oboljenja mogu dovesti i do smrti domaćina (Batista 1989). To svojstvo nastoji se iskoristiti u suzbijanju i regulaciji populacija štetnih organizama, odnosno biološkoj kontroli. Od 1960-ih brojni proizvodi na bazi entomopatogenih gljiva formulirani su, proizvedeni i uspješno korišteni te uporaba entomopatogenih gljiva u biološkoj kontroli (ponajviše poljoprivrednih štetnika) dobiva sve veću važnost (Faria i Wraight 2007; Mascarin i Jaronski 2016).

Za razliku od drugih patogenih mikroorganizama na kukcima kao što su bakterije, virusi i mikrosporidije, koji u domaćina ulaze i vrše zarazu preko probavnog trakta, entomopatogene gljive to uglavnom čine direktnim prodiranjem kroz kutikulu (Evans i Hywel-Jones 1997). Nakon prianjanja na površinu tijela kukca u povoljnim uvjetima spore (konidije) klijaju (formiraju penetrirajuće strukture, tzv. klijajuće cijevi i apresorije) te kombinacijom enzimatske aktivnosti i mehaničkog pritiska ulaze $u$ unutrašnjost kukca (Ortiz-Urquiza i Keyhani 2013). Iz apresorija izlaze penetrirajuće hife koje svojim rastom dolaze do hemocela gdje klijaju u nove vegetativne jednostanične strukture zvane blastospore, koje koloniziraju unutrašnje tkivo i uzimaju hranjive tvari za svoj brzi rast i reprodukciju (Humber 2008). Inkubacijski period ovisi o domaćinu i njegovu razvojnom stadiju, soju gljive i njegovoj virulentnosti te temperaturi. Ubrzo nakon smrti hife izlaze iz kukca i u povoljnim okolišnim (prvenstveno vlažnim) uvjetima produciraju spore (zračne konidije) koje se dalje prenose vjetrom, kišom i drugim abiotičkim i biotičkim faktorima (slika 1.).

Hrastova mrežasta stjenica, Corythucha arcuata (Heteroptera, Tingidae) značajni je štetnik na hrastu lužnjaku (Quercus robur L.) te se nakon svog pridolaska u područje Europe vrlo brzo proširila u velik broj zemalja uzrokujući preuranjeno naglašeno žućenje i klorotičnost listova, koja nastaje sisanjem biljnih sokova. Prirodni neprijatelji ovog invazivnog organizma do sada su bili slabo istraživani, no otkriće entomopatogenih gljiva kao uzročnika uginuća odraslih jedinki pronađenih u mahovini na području spačvanskog bazena (Kovač i sur. 2020) produbilo je potrebu za provedbom takvih istraživanja. S obzirom na to da entomopatogene gljive mogu biti važan faktor $u$ regulaciji brojnosti nekog štetnog kukca te su sposobne izazvati veći mortalitet i čak slom cijele populacije prenamnoženog štetnika (prikazano u primjerice Aoki 1974; Fuxa i Tanada 1987; Hicks i Watt 2000; Matek i Pernek 2018), njihov značaj nije zanemariv. 


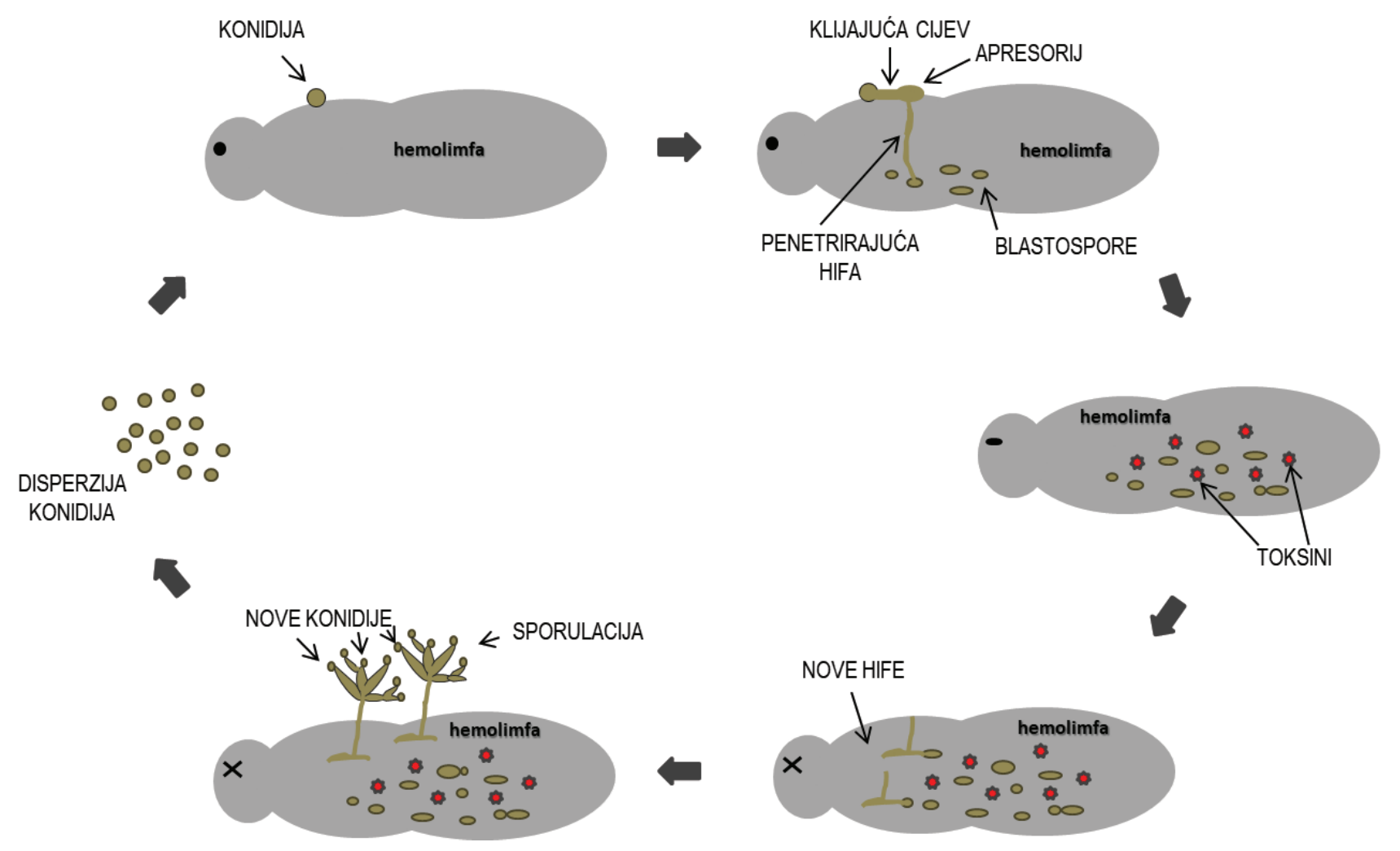

Slika 1. Proces infekcije entomopatogenim gljivama, razvoj bolesti, smrt kukca i redisperzija konidija

Figure 1. The process of infection with entomopathogenic fungi, disease development, insect death and redispersion of conidia

U istraživanju Kovač i sur. (2021) od 65\% pronađenih mrtvih prezimljavajućih jedinki u mahovini na njih 19\% utvrđena je zaraza entomopatogenim gljivama nakon čega su morfološke analize pokazale da od toga čak $70 \%$ pripada vrsti Beauveria pseudobassiana Rehner et Humber (Hypocreales: Cordycipitaceae). Navedeno je pokazalo da u mahovini postoji prirodni inokulum ovih gljiva te da one igraju ulogu u prirodnoj redukciji populacije ovog štetnika. Stoga, cilj je ovog istraživanja bio utvrditi brojnost prezimljavajućih imaga hrastove mrežaste stjenice $u$ mahovini te utvrditi njihov prirodni mortalitet i prirodni inokulum entomopatogenih gljiva, tj. njihovu prisutnost kao prirodnih neprijatelja u prezimljavajućoj generaciji, a dobivene rezultate usporediti s podacima iz 2019. godine kako bi se nastavila pratiti dinamika populacije ovog štetnika.

\section{Materijali i metode-Materials and Methods}

Uzorci mahovine sakupljani su u ožujku 2021. godine na trima lokalitetima na području spačvanskog bazena, koji su već istraživani u istom mjesecu 2019. godine kod Kovač i sur. (2021) (lokacija 3, 4 i 5) i korištenjem iste metodologije (u ožujku 2020. godine istraživanje nije provedeno zbog tadašnje situacije ograničenih uvjeta kretanja i rada uzrokovanih proglašenjem pandemije). Podaci o istraživanim lokacijama prikazani su u tablici 1. 
Tablica 1. Podaci o istraživanim lokacijama

Table 1. Data on study localities

\begin{tabular}{|c|c|c|c|}
\hline & LOKACIJA 1 & LOKACIJA 2 & LOKACIJA 3 \\
\hline \multirow[b]{2}{*}{ koordinate } & $45^{\circ} 08^{\prime} 45.7^{\prime \prime} \mathrm{N}$ & $44^{\circ} 59^{\prime} 41.1^{\prime \prime} \mathrm{N}$ & $45^{\circ} 02^{\prime} 22.5^{\prime \prime} \mathrm{N}$ \\
\hline & $\begin{array}{l}18^{\circ} 48^{\prime} 16.6^{\prime \prime} \mathrm{E} \\
\text { (Privlaka) }\end{array}$ & $\begin{array}{c}18^{\circ} 48^{\prime} 33.6^{\prime \prime} \mathrm{E} \\
\text { (Posavski Podgaici) }\end{array}$ & $\begin{array}{l}18^{\circ} 53^{\prime} 16.4^{\prime \prime} \mathrm{E} \\
\text { (Vrbania) }\end{array}$ \\
\hline \multirow{3}{*}{ opis } & Šumarija Otok & Šumarija Gunja & Šumarija Vrbanja \\
\hline & GJ Otočke šume & GJ Desićevo & GJ Vrbanjske šume \\
\hline & Odjel 14c & Odjel 12d & Odjel 71b \\
\hline
\end{tabular}

Kao i u prethodnom istraživanju na svakoj lokaciji sakupljeno je po $1 \mathrm{~m}^{2}$ mahovine s deset stabala po lokaciji, a uzorci su odneseni u Laboratorij za fitopatološka istraživanja Hrvatskog šumarskog instituta na daljnju analizu. Iz svakog komadića mahovine prezimljavajuće jedinke hrastove mrežaste stjenice pažljivo su odvajane i prebrojavane te razvrstavane $\mathrm{u}$ tri kategorije: žive, mrtve i zaražene (slika 2.). Također, mrtve jedinke (jedinke koje i nakon stavljanja u optimalne uvjete temperature nisu pokazivale znakove života) pohranjivane su u laboratorijske uvjete inducirane vlage radi potencijalnog razvoja entomopatogenih gljiva i njihove analize, odnosno radi ispitivanja uzročnika uginuća jedinki. Kroz dva tjedna sve su jedinke mikroskopski pregledane, a na kraju se računao prosječan broj prezimljavajućih i zaraženih jedinki u $1 \mathrm{~m}^{2}$ mahovine računajući sve tri lokacije te su se podaci uspoređivali s onima iz ožujka 2019. godine (Kovač i sur. 2021).
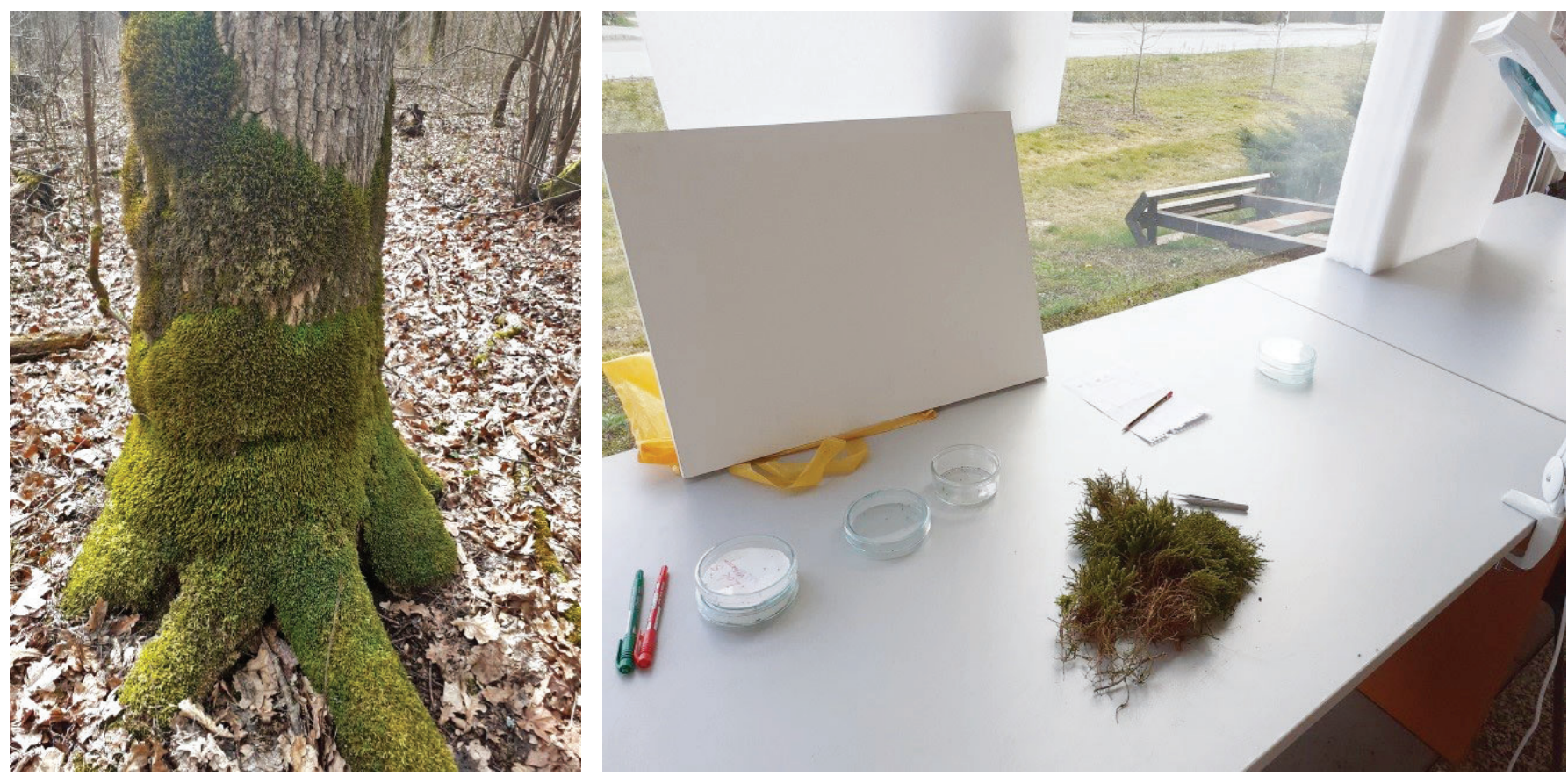

Slika 2. Uzorkovana mahovina s podnožja stabla; brojanje i analiza prezimljavajućih stjenica u laboratoriju

Figure 2. Sampled moss from the tree base; counting and analysis of overwintering oak lace bug in the laboratory 


\section{Rezultati i rasprava - Results and Discussion}

U usporedbi s podacima o brojnosti prezimljavajuće populacije u spačvanskom bazenu iz Kovač i sur. (2021) uočava se smanjenje broja prezimljavajućih imaga po $\mathrm{m}^{2}$ mahovine u prosjeku na trima ispitivanim lokalitetima (slika 3.), što može biti dobar pokazatelj prirodnog opadanja populacije ovog štetnika, no tek s gušćom mrežom uzorkovanja, odnosno većim brojem uzoraka na više lokaliteta navedeno bi se moglo tvrditi.

\section{broj prezimljavajućih imaga po $\mathrm{m}^{2}$ mahovine}

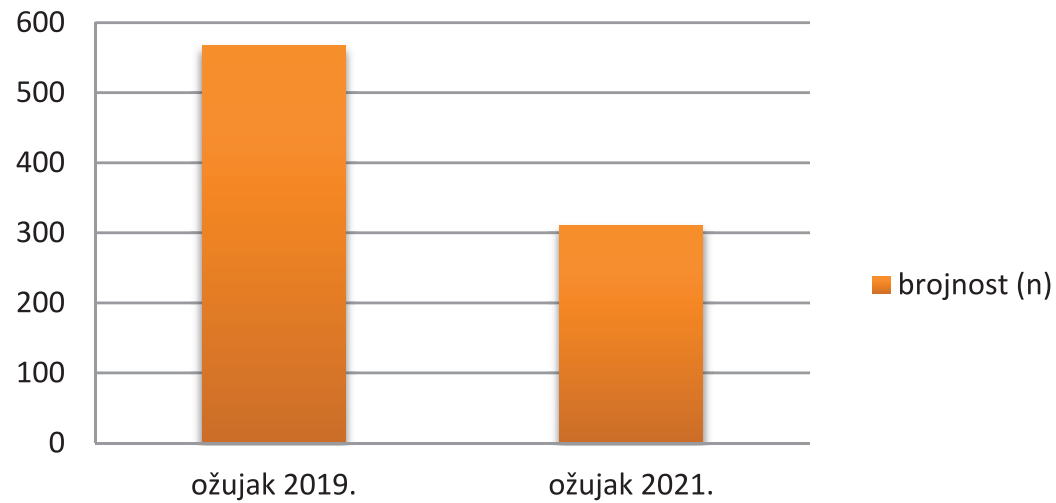

Slika 3. Grafički prikaz razlike u prosječnoj brojnosti imaga prezimljavajuće generacije hrastove mrežaste stjenice 2019. i 2021. godine na ispitivanim lokalitetima u Spačvi

Figure 3. Difference in the average number of adults of the overwintering generation of oak lace bug in 2019 and 2021 at the study localities in Spačva

Kao što su pokazali i rezultati istraživanja u Kovač i sur. (2021), prezimljavajuća generacija ima vrlo visoki mortalitet, koji je 2019. godine iznosio u prosjeku $65 \%$ na trima ispitivanim lokalitetima u spačvanskom bazenu, dok je u 2021. godini iznosio u prosjeku $64 \%$ na istim ispitivanim lokalitetima. Udio zaraze entomopatogenim gljivama u ovom istraživanju iznosio je 19\%, od čega je udio Beauveria sp. gljiva bio $14 \%$, dok je udio ostalih (još uvijek neidentificiranih) gljiva iznosio 5\%. Usporedbom s rezultatima iz 2019. godine (Kovač i sur. 2021) gdje je udio zaraze entomopatogenim gljivama iznosio 13\%, od čega je udio Beauveria sp. gljiva bio 9\%, a udio ostalih gljiva $4 \%$, uočava se porast broja zaraženih jedinki (slika 4.), što ukazuje na povećanje prirodnog inokuluma entomopatogenih gljiva $u$ prezimljavajućoj generaciji od $6 \%$, odnosno $5 \%$ za Beauveria sp. gljive. Navedeno povećanje prirodnog inokuluma ukazuje na redukcijski potencijal entomopatogenih gljiva i moguću ulogu koju ti organizmi imaju u prirodnoj regulaciji populacija hrastove mrežaste stjenice, a koja bi s vremenom mogla biti sve važnija. Također, rezultati pokazuju da je mortalitet ostao gotovo isti bez obzira na povećanje prirodnog inokuluma, što može značiti da postoji određeni horizontalni, a možda i vertikalni prijenos infekcije unutar populacije, što bi svakako trebalo ispitati u budućim istraživanjima. 


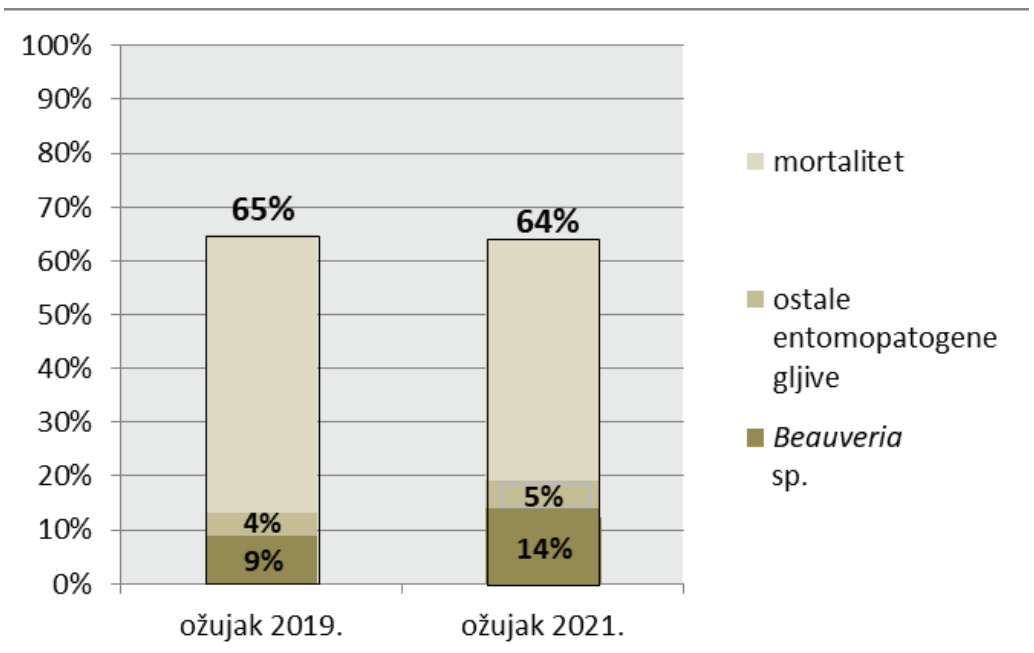

Slika 4. Grafički prikaz razlike u prosječnom mortalitetu i zarazi prezimljavajuće generacije hrastove mrežaste stjenice entomopatogenim gljivama u 2019. (Kovač i sur. 2021) i 2021. godini na ispitivanim lokalitetima u Spačvi

Figure 4. Difference in the average mortality and infection of oak lace bug generation with entomopathogenic fungi in 2019 (Kovač et al. 2021) and 2021 at the study localities in Spačva

U ukupnom udjelu zaraženih jedinki njih čak 75\% bilo je zaraženo Beauveria sp. gljivama (slika 5.), što dodatno potvrđuje da upravo ove vrste u najvećem postotku prirodno pridolaze na hrastovoj mrežastoj stjenici.

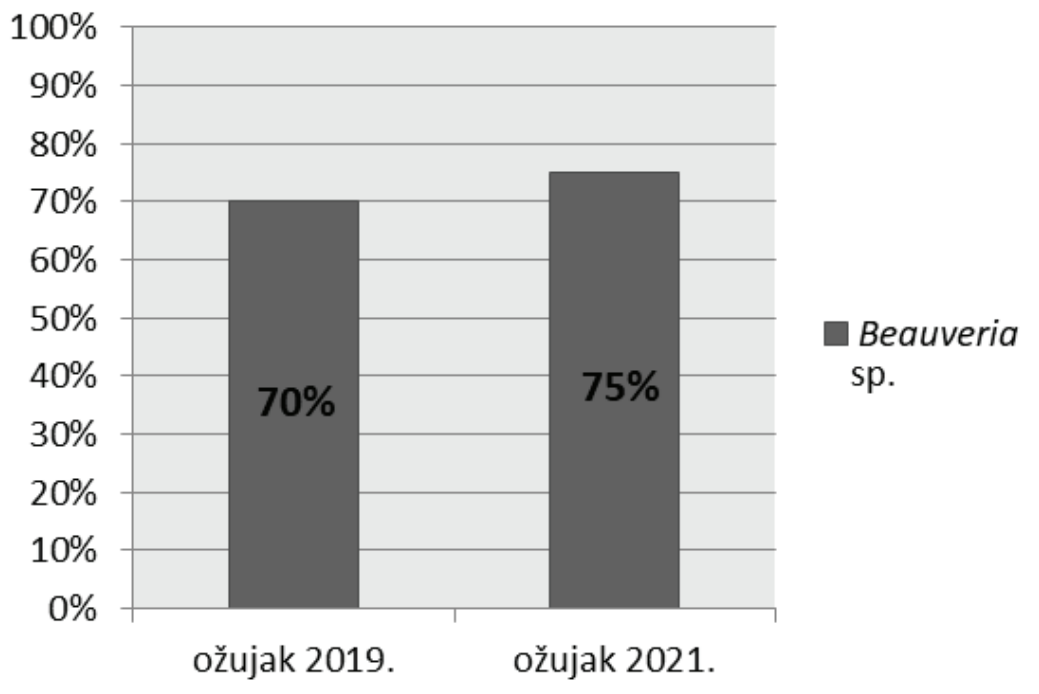

Slika 5. Udio zaraze Beauveria sp. gljivama u ukupnom udjelu zaraženih jedinki prezimljavajuće generacije hrastove mrežaste stjenice 2019. (Kovač i sur. 2021) i 2021. godine na ispitivanim lokalitetima spačvanskog bazena

Figure 5. The share of Beauveria sp. infection in the total share of infested adults of the oak lace bug overwintering generation in 2019 (Kovač et al. 2021) and 2021 at the study localities in Spačva

Korištenje sojeva gljiva roda Beauveria koji su već prisutni u populaciji hrastove mrežaste stjenice kao prirodni neprijatelji (slika 6.) predstavlja ekološki prihvatljiviju alternativu dosadašnjim metodama suzbijanja ovog invazivnog štetnika, a s obzirom na to da su istraživanja provedena u laboratoriju već pokazala njihovu učinkovitost (Kovač i sur. 2021) buduća istraživanja trebaju biti usmjerena na njihovu proizvodnju i praktičnu primjenu u terenskim tretiranjima. 


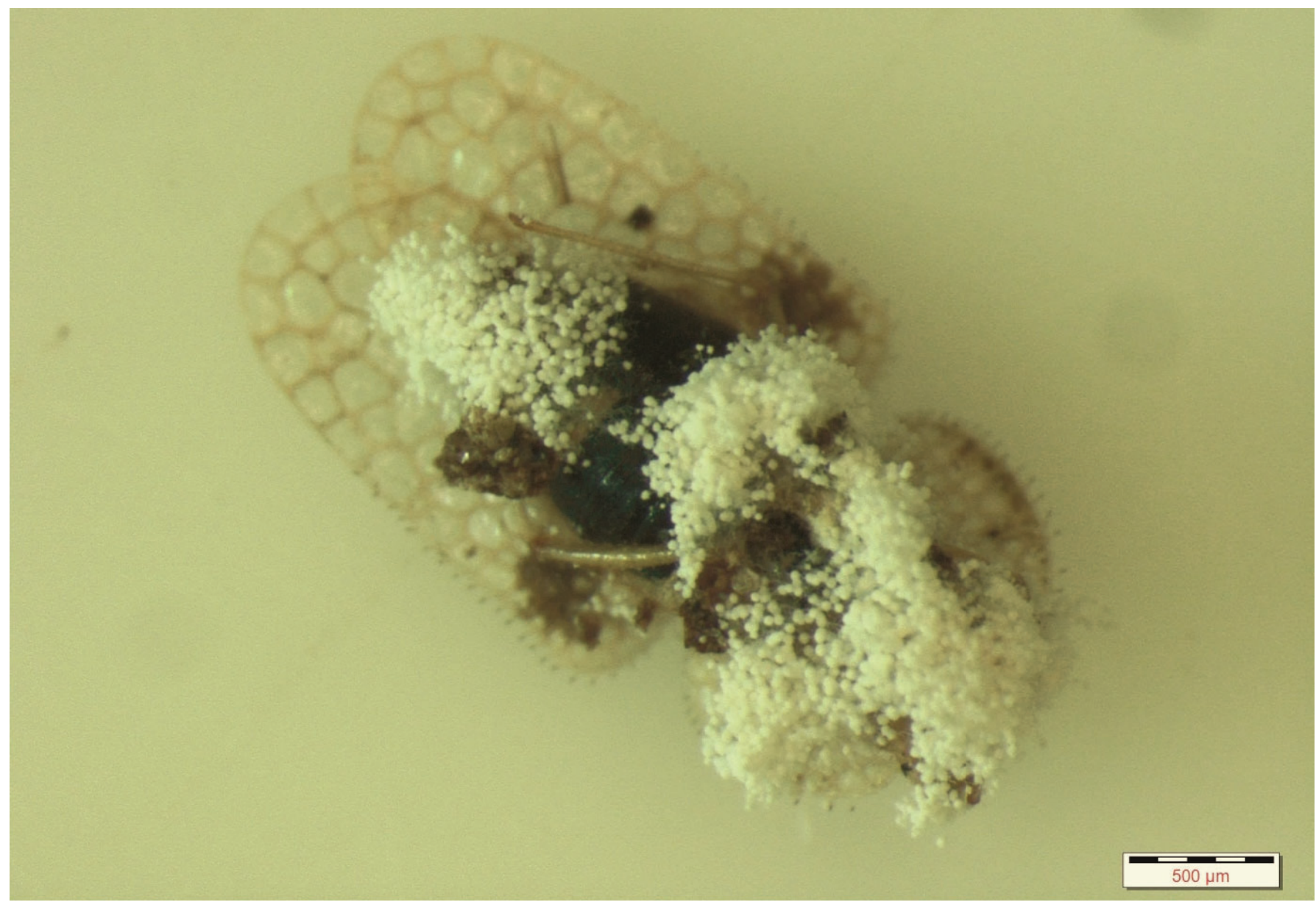

Slika 6. Imago hrastove mrežaste stjenice zaražen gljivom Beauveria pseudobassiana

Figure 6. Oak lace bug adult infested with fungus Beauveria pseudobassiana

Općenito, zbog sve većeg postrožavanja mjera uporabe kemijskih sredstava u šumarstvu i sve učestalijeg okretanja biološkim metodama suzbijanja štetnih organizama, otkrivanje novih vrsta i sojeva entomopatogenih gljiva i istraživanje metoda njihove primjene predstavlja velik potencijal za biološku kontrolu različitih ekonomski važnih i/ili invazivnih vrsta šumskih štetnika. Ovakva istraživanja još uvijek nisu dovoljno prepoznata u Hrvatskoj, a entomopatologija predstavlja nedovoljno istraživano područje šumarske entomologije, koje bi u skladu sa svjetskim trendovima trebalo razvijati i uključivati kao komponentu u integriranom sustavu zaštite šuma.

\section{Zahvala - Acknowledgments}

Zahvaljujem se tehničarima Hrvatskog šumarskog instituta (Jastrebarsko) Zlatku Huljini i Nikolini Milanović na pomoći pri sakupljanju i laboratorijskoj obradi uzoraka. 


\section{Literatura - References}

Aoki, J. 1974. Mixed infection of the gypsy moth, Lymantria dispar japonica Motschulsky (Lepidoptera: Lymantriidae), in a larch forest by Entomophaga aulicae (Reich.) Sorok. and Paecilomyces canadensis (Vuill.) Brown et Smith. Applied Entomology and Zoology. 9 (3): 185-190.

Batista, F.A. 1989. Controle biológico e o manejo integrado de pragas. Biológico. 55: 36-39.

Evans, H.C., Hywel-Jones, N.L. 1997. Entomopathogenic fungi. In: World Crop Pests 7, Elsevier, pp. 3-27.

Faria, M.R.D., Wraight, S.P. 2007. Mycoinsecticides and Mycoacaricides: A comprehensive list with worldwide coverage and international classification of formulation types. Biological Control. 43: 237-256.

Fuxa, J.R., Tanada, Y. 1987. Epizootiology of insect diseases. Wiley-Interscience, ISBN047187812X, New York.

Hicks, B.J., Watt, A.D. 2000. Fungal disease and parasitism in Panolis flammea during 1998: evidence of change in the diversity and impact of the natural enemies of a forest pest. Forestry. 73 (1): 31-36.

Humber, R.A. 2008. Evolution of entomopathogenicity in fungi. Journal of Invertebrate Pathology. 98: 262-266.

Kovač, M., Gorczak, M., Wrzosek, M., Tkaczuk, C., Pernek, M. 2020. Identification of Entomopathogenic Fungi as Naturally Occurring Enemies of the Invasive Oak Lace Bug, Corythucha arcuata (Say) (Hemiptera: Tingidae). Insects. 11 (10): 679.

Kovač, M., Linde, A., Lacković, N., Bollmann, F., Pernek, M. 2021. Natural infestation of entomopathogenic fungus Beauveria pseudobassiana on overwintering Corythucha arcuata (Say) (Hemiptera: Tingidae) and its efficacy under laboratory conditions. Forest Ecology and Management. 491: 119193.

Matek, M., Pernek, M. 2018. First Record of Dendrolimus pini Outbreak on Aleppo Pine in Croatia and Severe Case of Population Collapse Caused by Entomopathogen Beauveria bassiana. South-east European Forestry. 9 (2): $91-96$.

Mascarin, G.M., Jaronski, S.T. 2016. The production and uses of Beauveria bassiana as a microbial insecticide. World Journal of Microbiology and Biotechnology. 32 (11): 177.

McCoy, C.W., Samson, R.A., Boucias, D.G. 1988. Entomogenous fungi. In: Ignoffo, C., Mandava, N.B. (eds) CRC Handbook of Natural Pesticides, Vol 5. Microbial Insecticides, Part A: Entomogenous Protozoa and Fungi. CRC Press, Boca Raton, Florida, pp. 151-234.

Ortiz-Urquiza, A., Keyhani, N.O. 2013. Action on the surface: entomopathogenic fungi versus the insect cuticle. Insects. 4: 357-374.

Roberts, D.W., Humber, R.A. 1981. Entomogenous fungi. In: Cole, G.T., Kendrick, B. (eds) Biology of Conidial Fungi. Academic Press, New York, pp. 201-236.

Samson, R., Evans, H., Latgé, J.P. 1988. Atlas of Entomopathogenic Fungi, 1st ed. Springer, Berlin/Heidelberg, Germany, p. 187.

St. Leger, R.J., Wang, C. 2010. Genetic engineering of fungal biocontrol agents to achieve efficacy against insect pests. Applied Microbiology and Biotechnology. 85: 901-907.

Wraight, S., Inglis, G., Goettel, M. 2007. Fungi. In: Lacey, L., Kaya, H. (eds) Field Manual of Techniques in Invertebrate Pathology, 2nd ed. Springer, Dordrecht, The Netherlands, pp. 223-248. 